\title{
EL PAPEL DEL TRIBUNAL CONSTITUCIONAL EN EL ESTADO AUTONÓMICO
}

\author{
FRANCISCO PÉREZ DE LOS COBOS ORIHUEL
}

Presidente Emérito del Tribunal Constitucional

SUMARIO

I. La definición constitucional del Estado autonómico y el papel del Tribunal Constitucional. II. Aportaciones del Tribunal Constitucional a la construcción y defensa del Estado autonómico. III. Ante el horizonte de una reforma constitucional.

\section{LA DEFINICIÓN CONSTITUCIONAL DEL ESTADO AUTONÓMICO Y EL PAPEL DEL TRIBUNAL CONSTITUCIONAL.}

Para comprender el trascendental papel que al Tribunal Constitucional ha correspondido en la construcción del Estado autonómico es indispensable partir de la letra de la Constitución, de las genéricas y abiertas previsiones del Título VIII de la misma, en las que hoy resulta difícilmente reconocible la realidad imponente del Estado autonómico.

En efecto, se ha repetido hasta la saciedad pero hay que reiterarlo, de las tres grandes decisiones que la transición prefiguró, el Estado democrático, la Monarquía parlamentaria y el sistema de autonomías territoriales, la Constitución reguló y concretó las dos primeras, pero no lo hizo con la tercera que fue, en buena medida, «desconstitucionalizada» y diferida a un momento posterior: el del establecimiento de los Estatutos de Autonomía ${ }^{1}$. El de la definición del modelo territorial de Estado fue, sin duda, el más trascendental de los numerosos compromisos dilatorios y apócrifos que la Constitución recogió.

La «desconstitucionalización» de la estructura territorial del Estado no fue, sin embargo, plena, pues la Constitución incorporó un importante conjunto de

1 Sigo en este punto a Aragón, M, «La construcción del Estado autonómico», en Estudios de Derecho Constitucional, CEPC, Madrid, 2013, pp. 826 y 827. 
previsiones destinadas a regir el proceso de construcción autonómica y a limitar el alcance y contenidos de los propios Estatutos de Autonomía. Dicho en otros términos, aunque la Constitución no diseñó un definido modelo de Estado desde el punto de vista de la organización territorial, estableció eso sí un marco estructural y unos principios y previsiones básicas que debían respetarse a la hora de ejercer el derecho a la autonomía que reconoció a nacionalidades y regiones ${ }^{2}$.

En este sentido, la Constitución determinó que habría solo un Estado (art. 1.1), que la Nación española se caracteriza por su «indisoluble unidad» (art. 2) y que la soberanía nacional reside en el pueblo español (art. 1.2); que las «nacionalidades y regiones» tenían reconocido y garantizado el derecho a la autonomía y la solidaridad entre ellas (art. 2); que en el ejercicio del derecho a la autonomía se constituirían las «Comunidades autónomas» (art. 137), cuya existencia no podría implicar privilegios económicos o sociales (art. 138.2), teniendo todos los españoles los mismos derechos y obligaciones en cualquier parte del territorio del Estado (art. 139.1); que el acceso a la autonomía debía seguir ciertos procedimientos (arts. 143 y 151); que los Estatutos de Autonomía serían la norma institucional básica de las Comunidades Autónomas, organizadora de sus instituciones y atributiva de sus competencias (art. 147), aprobándose por Ley orgánica (art. 81) siguiendo unos cauces específicos (arts 146 y 151) ; que las competencias del Estado estaban fijas en una lista de materias (art. 149) y en otra las que podían asumir las Comunidades Autónomas (art. 148); que la autonomía del máximo grado sería política y comportaría la existencia de gobiernos y parlamentos propios (art. 152), es decir, que la división territorial del poder alcanzaría al legislativo y al ejecutivo, pero no al judicial, único en toda España (art. 117) ${ }^{3}$; que el Estado podría transferir o delegar en las Comunidades Autónomas, mediante ley orgánica, facultades correspondientes a materias de titularidad estatal susceptibles de ello por su propia naturaleza (art. 150.2) y, en fin, repárese en lo escueto de la previsión- que el Tribunal Constitucional conocería de «los conflictos de competencia entre el Estado y las Comunidades Autónomas o de los de éstas entre sí», permitiendo al Gobierno central impugnar las disposiciones y resoluciones adoptadas por los órganos de las Comunidades Autónomas (art. 161.1 y 2)

Estas fueron las previsiones constitucionales fundamentales, en el marco de las cuales la Constitución confió la puesta en marcha y la implementación del modelo territorial del Estado al llamado "principio dispositivo», que, aunque no formulado expresamente en la Constitución, ha sido junto a aquellas la clave de bóveda del Estado autonómico. Como ha puesto de relieve el Consejo de Estado, el principio dispositivo ha sido y es la principal manifestación de la apertura de

2 Ibidem, pag. 827. Por ello algunos rechazan el término «desconstitucionalización» y prefieren hablar de «constitucionalización incompleta» (Torres Del Moral, A, «Estado autonómico, segunda fase», Vera Santos, J.M, Díaz Revorio, F.J (coords.), La reforma estatutaria y constitucional, Madrid 2009, p. 47 y 68).

3 Ibidem. 
nuestro sistema de descentralización política y ha jugado tanto, en el momento de constitución de las Comunidades Autónomas, cuando los titulares del derecho a la autonomía originariamente lo ejercieron, como a la hora de determinar el acervo institucional y competencial correspondiente a cada Comunidad Autónoma en su Estatuto de Autonomía. Al amparo del mismo se han adoptado decisiones tan fundamentales como la configuración del mapa autonómico, los diferentes niveles de autogobierno, la asunción de competencias por las distintas Comunidades Autónomas y se han amparado sucesivas ampliaciones del marco competencial mediante la reforma de los Estatutos de Autonomía.

Pues bien, este original e insólito modelo de Estado, pergeñado sobre un escueto conjunto de previsiones fundamentales, muchas de ellas procedimentales, y el juego del principio dispositivo, se ha manifestado singularmente complejo en su configuración. Su estructural apertura, su condición de proyecto «in fieri», que fue probablemente un sensato hallazgo del constituyente para cerrar una Constitución que urgía, al prolongarse «sine die» ha producido, en palabras de Rubio Llorente, la anomalía de «un proceso constituyente permanentemente abierto» y de un modelo de Estado instalado «en la provisionalidad» ${ }^{4}$. Una apertura y una provisionalidad que requerían para hacerse hacederas y practicables de la permanente renovación del consenso constituyente y de la práctica de una contínua labor de diálogo y compromiso político, que por desgracia no han tenido ni la continuidad ni el alcance que hubieran sido deseables. En efecto, el compromiso abierto que fue la regulación del modelo de Estado en la Constitución del 78 requería para funcionar cabalmente de su paulatina renovación y quizás de su cierre, pero la una y el otro pasaban por la suscripción de pactos políticos, que solo en las fases iniciales del desarrollo autonómico se produjeron, pues la propia definición del modelo se ha visto a menudo sometida al juego partidario. La propia estructura del sistema de reparto de poder, en fin, en el que interactúan en tensión permanente diversos actores, capaces todos de mermar y/o condicionar el poder de los demás, en el que las previsiones constitucionales y estatutarias de distribución competencial no han sido por decirlo levemente un dechado de claridad y en el que han escaseado los mecanismos de negociación y cooperación políticas tendentes a soslayar o minimizar los conflictos — si bien se repara el único instrumento de solución de conflictos al que alude la Constitución resulta ser el Tribunal Constitucional—, completan el panorama de nuestra complejidad.

En este escenario difícil y, sobre la base, de los semielaborados preceptos del Título VIII de la Constitución, al Tribunal Constitucional ha correspondido la ardua tarea de «definir» el Estado autonómico, fundamentalmente en lo que se refiere al reparto de competencias, y de defenderlo frente a embates de no menor envergadura provenientes de diversos frentes, una tarea que seguramente excede

4 Rubio Llorente, F; «Sobre la conveniencia de terminar la Constitución antes de acometer su reforma», La forma del poder. Estudios sobre la Constitución, Tomo II, CEPC, $3^{\text {a }}$ ed, Madrid, 2012 pp. 820 y 821. 
la que debiera serle propia pero que no ha tenido más remedio que desempeñar. En efecto, ante un modelo territorial «in fieri» y ante la falta de acuerdos o decisiones políticas generales que objetivasen el modelo, ha sido el Tribunal, a golpe de sentencia, el que ha venido a perfilar el sistema haciendo efectivo el riesgo, sobre el que ya lúcida doctrina llamó la atención en la primera hora, de un «Estado jurisdiccional autonómico» ${ }^{5}$, con el inevitable desgaste que para la institución este desempeño ha supuesto. Del alcance de este papel resulta elocuente el dato de las más de mil sentencias dictadas por el Tribunal en conflictos de competencia en sus treinta y siete años de existencia, al que habría que sumar el de los recursos de inconstitucionalidad con dimensión competencial, muy abundantes como es sabido.

\section{APORTACIONES DEL TRIBUNAL CONSTITUCIONAL A LA CONSTRUCCIÓN Y DEFENSA DEL ESTADO AUTONÓMICO}

Las contribuciones que la jurisprudencia del Tribunal Constitucional ha hecho a la construcción del Estado autonómico son de mayor cuantía. Al Tribunal le ha correspondido dar cuerpo a muchas de las normas constitucionales semielaboradas que el Título VIII recoge, construir categorías que sólo en ciernes pueden leerse en él y sentar principios, criterios y técnicas de articulación materialmente constitucionales que han resultado capitales en la construcción del Estado autonómico. Sería necesario ser muy prolijo para dar justa cuenta de lo que esta labor de construcción, en general bien valorada por la doctrina, ha significado, pero no quisiera dejar de mencionar, siquiera sea a título de ejemplo, algunas de sus aportaciones, sin el concurso de las cuales el Estado autonómico no hubiera podido funcionar:

1. La primera elaboración de nuestra jurisprudencia que quisiera destacar es la de la noción misma de autonomía y de su inserción en el sistema constitucional de fuentes. Desde la primera hora el Tribunal sostuvo que la autonomía de las Comunidades Autónomas, reconocida por la Constitución, era una autonomía política y no mera autonomía administrativa o de gestión (SSTC 4/1981, FJ3; 25/1981, FJ3 y 247/2007, FJ 4), pues, en sus propios términos, las CCAA son «corporaciones públicas de base territorial y naturaleza política» (STC 25/1981, FJ 3). Una autonomía, sin embargo, que no es soberanía y que no puede oponerse al principio de unidad porque es «precisamente dentro de éste donde alcanza su verdadero sentido, como expresa el artículo 2 de la Constitución» (STC 4/1981, FJ3). Por lo que se refiere a las normas institucionales básicas a través de las

5 Aragón Reyes, M, «Comentario al art. 161 de la CE», Alzaga Villaamil, O (dir); Comentarios a las Leyes Políticas, Tomo XII, p. 210 y ss. En contra de esta denominación, que yo comparto, Torres DeL Moral, A, «Estado autonómico, segunda fase», Vera Santos, J.M, Díaz Revorio, F.J (coords.), La reforma estatutaria y constitucional, Madrid 2009, p. 69. 
cuales el derecho a la autonomía se ejerce, a los Estatutos de Autonomía, el Tribunal definió su posición en el Ordenamiento jurídico desde una doble perspectiva. Si de una parte dejó bien claro que se trata de normas jerárquicamente subordinadas a la Constitución, de manera que han de ser siempre interpretadas dentro de la misma (SSTC 69/1982, FJ 1; 76/1983, FJ 4), lo que vino a garantizar la supremacía de la Constitución en el marco de la distribución de competencias, de otro tuteló su singular posición en el Ordenamiento, su invulnerabilidad frente a otras leyes del Estado, su integración en el bloque de constitucionalidad y su consiguiente consideración como parámetro para el enjuiciamiento de las normas legales (STC 247/2007, FJ12).

2. Por lo que respecta al reparto competencial que resulta de la Constitución y de los Estatutos de Autonomía, quisiera destacar la importantísima elaboración del Tribunal en la conceptuación de los binomios bases estatales/legislación autonómica de desarrollo y legislación estatal/ejecución autonómica. La noción de bases, a la que con buen criterio el Tribunal ha reconducido las diversas expresiones homólogas utilizadas por el constituyente, y que cumple la importante función de delimitar el ámbito de la competencia autonómica de desarrollo legislativo, presenta de acuerdo con nuestra jurisprudencia una doble dimensión, material y formal, debiendo en todo caso para que pueda hablarse de bases estatales concurrir ambas. Aunque fundamentalmente estas dimensiones se traducen, de una parte, en el denominador normativo común o elementos fundamentales de la regulación de una materia, de suerte que se aseguren de manera unitaria y en condiciones de igualdad los intereses generales (SSTC 1/1982 y 109/2003), y de otra, en una preferencia por la ley para su regulación y en la exigencia de que la norma básica manifieste o exprese su condición de tal (STC 69/1988, FJ5), la propia jurisprudencia constitucional ha abierto espitas flexibilizadoras de esta noción y, con posterioridad, evitado que se las cierren.

El binomio legislación estatal/ejecución autonómica fue también tempranamente delimitado por nuestra jurisprudencia sobre la base del rechazo a una interpretación formal y literal de los términos legislación y ejecución. «Cuando la Constitución — ha dicho el Tribunal— usa el término «legislación» y lo atribuye a la competencia estatal incluye los reglamentos tradicionalmente denominados ejecutivos, esto es, los dictados en desarrollo de la Ley y complementarios de la normativa en ella recogida con la finalidad de mantener una uniformidad en la ordenación jurídica de la materia» (SSTC 100/1991 y 196/1997).

3. En este mismo ámbito de la articulación competencial, es asimismo muy relevante la doctrina constitucional sobre las reglas y principios que rigen las relaciones entre el ordenamiento estatal y los autonómicos. Por citar sólo algunos relevantes: (i) La formulación, a la hora de resolver los conflictos competenciales, de la regla de prevalencia de las competencias especiales sobre las generales, pauta interpretativa que ha evitado el vaciamiento de los títulos competenciales más específicos (STC 45/2011, FJ 8); (ii) El principio de territorialidad como límite de las competencias autonómicas, pues el ejercicio de la competencia «debe tener 
como soporte y presupuesto el territorio en el cual esa Comunidad ejerza sus potestades»( STC 195/2001, FJ 3); (iii) La lectura minimizadora del principio de prevalencia del derecho estatal contemplado en el art 149.3 CE que ha vaciado prácticamente de contenido al principio en cuestión, a la que reciente jurisprudencia quiere poner coto ( STC. 102/2016, FJ 3 y ss.); (iv) La formulación del principio de «lealtad constitucional», en el que el Tribunal ha visto un «soporte esencial del funcionamiento del Estado autonómico», que ha de presidir «las actuaciones del Estado y las Comunidades Autónomas» y del que deriva un deber de auxilio y colaboración recíprocos (SSTC 42/2014, FJ 4; 215/2014, FJ 4).

Podrán, sin duda o criticarse estas y otras elaboraciones jurisprudenciales efectuadas por el Tribunal en su dilatada historia, pero lo que no puede negarse es el notable esfuerzo de construcción que ha realizado, sin el cual el estado autonómico no resulta imaginable.

4. Un último ejemplo, en fin, de la labor del Tribunal en este ámbito ha sido su doctrina sobre la incidencia del Derecho europeo en el reparto competencial entre el Estado y las CCAA. Como el Tribunal ya señaló en su STC 252/1988 — y ha venido repitiendo a lo largo de estos años - la ejecución del Derecho de la Unión no altera el orden interno de distribución competencial entre el Estado y las Comunidades Autónomas, no pudiendo verse en el derecho comunitario un título competencial, ni en favor del Estado, ni en favor tampoco de las Comunidades Autónomas.

Por consiguiente, la aplicación interna del Derecho europeo corresponde a quien «materialmente» o «naturalmente» ostente la competencia según las reglas de Derecho interno. Cuando, en consecuencia, de acuerdo con la distribución constitucional y estatutaria de competencias la competencia material sobre la norma europea corresponda a la Comunidad Autónoma deberá ser ésta quien la ejecute o transponga.

El importantísimo haber del Tribunal Constitucional en la construcción del Estado autonómico no está exento de sombras a algunas de las cuales no quiero dejar de referirme. La primera, que atañe al propio funcionamiento del Tribunal y que se ha intentado paliar o remediar, es el notable retraso con el que el tribunal resuelve muchas cuestiones competenciales, no pocas veces abordadas cuando la norma impugnada ha sido ya derogada. El ingente número de recursos que el Tribunal conoce y la trascendencia de muchos de ellos explica pero no justifica este retraso, pues quizás singularmente en el ámbito competencial, cuando se debate sobre la estructura misma del Estado, la justicia tardía no es una buena justicia.

La segunda ligada al propio «modelo» constitucional de distribución del poder y a las limitaciones inherentes al método tópico-jurídico con el que el Tribunal ha debido enfrentar su tamaña tarea, atañe a la propia construcción jurisprudencial sobre la distribución de competencias, en la que no faltan contradicciones e incoherencias puntuales y, que globalmente apreciada, como ha subrayado el presidente 
Rodríguez Bereijo, no consiente, como seguramente debiera, una clara definición de quién hace qué.

Resulta una obviedad recordar que la jurisprudencia del Tribunal no se hace en abstracto sino resolviendo concretas controversias competenciales y resolviendo los concretos litigios sometidos en cada momento a nuestro enjuiciamiento, lo que hace inevitable que «las circunstancias específicas concurrentes en cada caso (...) lleguen a modular ampliamente, cuando no a excepcionar sin más, esas reglas o criterios generales ${ }^{6}$ que el propio Tribunal se ha dado. En este sentido, pueden en ocasiones apreciarse en ella inflexiones e incoherencias en el uso y la aplicación de determinadas categorías y conceptos o en la interpretación del alcance de determinados títulos competenciales. Estas disfunciones son, sin embargo, casi inevitables habida cuenta de las limitaciones de la aproximación jurisprudencial a la cuestión y las muy diversas coyunturas en las que el Tribunal ha debido hacer su tarea. Más interesante resulta, sin embargo, preguntarse si, a resultas de la compleja regulación competencial constitucional y estatutaria y de la práctica política, la lectura jurisprudencial de la distribución competencias no ha producido de facto un sistema en el que casi todas, por no decir todas, las competencias son compartidas o concurrentes, abundando con ello en la no escasa complejidad del mismo ${ }^{7}$.

Por lo que se refiere a la defensa del Estado autonómico, creo que a lo largo de treinta y siete años de historia el Tribunal ha debido enfrentar - y con mayor o menor acierto formal ha sabido hacerlo — importantes desafíos al modelo territorial pergeñado por la Constitución del 78. Y lo ha hecho con independencia de cual fuera el origen de los mismos y con notable coherencia en su lectura de la Constitución:

1. El primer momento importante en este sentido fue la STC 76/1983, en la que el Tribunal enjuició los recursos previos de inconstitucionalidad promovidos contra el proyecto de Ley Orgánica de Armonización del Proceso Autonómico (LOAPA), tutelando el proyecto de descentralización política que la Constitución representaba. En efecto, frente a las pretensiones uniformizadoras y armonizadoras del legislador estatal, el Tribunal rechazó sin ambages que el legislador pudiera incidir con carácter general en la configuración del modelo de distribución de

6 Fernández Farreres, G, La contribución del Tribunal Constitucional al Estado Autonómico, Iustel, Madrid 2005, pp. 196-198.

7 Tal es el parecer del Presidente emérito Rodríguez Bereijo, que literalmente ha escrito: «Y nuestro problema es la gran pregunta de toda descentralización política, sea cual sea la forma que adopte, Estado federal o regional: el reparto o la distribución de quién hace qué. En el caso español y de nuestra Constitución en el Título VIII, la conclusión es que «todos hacen todo», propiciado en gran medida por la tendencia de la interpretación del orden constitucional de reparto de competencias por el Tribunal Constitucional (y ya no digamos la práctica política) en el sentido de transformar las competencias exclusivas en competencias compartidas o concurrentes. Reduciendo cada vez más el ámbito de materias de competencia exclusiva del Estado» («La Constitución y la articulación territorial del Estado español», Cuadernos FAES, Octubre/Diciembre 2013, p. 29). 
competencias a través de instrumentos normativos distintos a la Constitución y a los Estatutos de Autonomía. «Sin una expresa previsión constitucional o estatutaria» - dijo entonces el Constitucional - el legislador estatal no puede emanar normas que incidan en el sistema de distribución de competencias «para integrar hipotéticas lagunas existentes en la Constitución», no puede "dictar normas meramente interpretativas, cuyo exclusivo objeto sea precisar el único sentido, entre los varios posibles, que deba atribuirse a un determinado concepto o precepto de la Constitución, pues, al reducir las distintas posibilidades o alternativas del texto constitucional a una sola, completa de hecho la obra del poder constituyente y se sitúa funcionalmente en su mismo plano, cruzando al hacerlo la línea divisoria entre el poder constituyente y los poderes constituidos». El legislador estatal no puede - fue la conclusión de la sentencia - llevar a cabo con pretensiones de validez general una interpretación general y abstracta de los preceptos que forman parte del bloque de la constitucionalidad. Esta doctrina constitucional descansa en la distinción entre el ámbito propio del poder constituyente y el propio del poder constituido, cuya custodia permanente corresponde al Tribunal Constitucional en tanto que supremo intérprete de la Constitución.

2. Si bien se repara esta misma doctrina fue la invocada por el Tribunal Constitucional más de treinta años después al enjuiciar - y es el segundo momento al que quiero referirme - los denominados Estatutos de Autonomía de segunda generación. En punto a la distribución de competencias estos Estatutos no vinieron tanto a recoger, a la antigua usanza, un listado de competencias autonómicas, cuanto a interpretar la Constitución, en particular su artículo 149.1 CE, definiendo, en algunos casos, el alcance funcional de cada tipo de competencia asumida y desglosando minuciosamente cada una de las materias con referencia a las submaterias que cada título competencial comprende, con la finalidad de evitar que sobre ellas pudieran incidir los títulos competenciales reservados al Estado. Repárese en el paralelismo con el caso anterior: si allí se pretendía condicionar la lectura de la Constitución desde la ley del Estado aquí quiso hacerse algo similar desde los nuevos textos estatutarios.

Sobre este nuevo paradigma de Estatutos de Autonomía ha debido pronunciarse el Tribunal Constitucional principalmente, entre otras, en las SSTC $247 / 2007$, de 12 de abril y 31/2010, de 28 de junio, que resuelven los recursos de inconstitucionalidad promovidos contra el Estatuto de Autonomía de la Comunidad Valenciana y el Estatuto de Autonomía de Cataluña, y en las que el Tribunal efectúa relevantes pronunciamientos sobre la posición de los Estatutos de Autonomía en el sistema de fuentes, su naturaleza, funciones y su contenido constitucional.

El Tribunal se ha mantenido fiel a su inicial doctrina sobre la posición de los Estatutos de Autonomía en el sistema de fuentes, su relación con la Constitución y el resto de normas, sobre su condición de norma atributiva de competencias autonómicas pero no estatales y sobre la prohibición de que el legislador estatutario lleve a cabo definiciones o interpretaciones de categorías y conceptos 
constitucionales. «Los Estatutos —reza nuestra STC 31/2010 — son las normas constitucionales habilitadas para la asignación de competencia a las respectivas Comunidades Autónomas en el marco de la Constitución (...) El Estatuto puede atribuir una competencia legislativa sobre determinada materia, pero qué haya de entenderse por «competencia» y qué potestades comprenda la legislativa frente a la competencia de ejecución son presupuesto de la definición misma del sistema (...) y, por tanto, reservados a la Norma primera que lo constituye. No es otro, al cabo, el sentido profundo de la diferencia entre el poder constituyente y el poder constituido ya advertido en la STC 76/1983, de 5 de agosto». «En su condición de intérprete supremo de la Constitución, el Tribunal Constitucional es el único competente para la definición auténtica —e indiscutible — de las categorías y principios constitucionales. Ninguna norma infraconstitucional, justamente por serlo, puede hacer las veces de poder constituyente prorrogado o sobrevenido, formalizando uno entre los varios sentidos que pueda admitir una categoría constitucional. Este cometido es privativo del Tribunal Constitucional» (..) «por un principio elemental de defensa y garantía de la Constitución».

La consecuencia de este planteamiento es la consideración como meramente descriptivo del desglose de potestades, facultades y funciones que de acuerdo con los nuevos Estatutos integraría el contenido funcional de las competencias asumidas por la Comunidad Autónoma, que, en todo caso, debe acomodarse a la jurisprudencia constitucional so pena de inconstitucionalidad (STC 31/2010, FJ 59 a 62 ).

3. El tercer momento al que quiero referirme es el presente, en el que el Tribunal se ha visto llamado a enjuiciar sendas graves declaraciones del Parlamento de Cataluña, una «de soberanía y del derecho a decidir del pueblo de Cataluña»(Resolución 5/X, de 23 de Enero 2013) y otra «sobre el inicio del proceso político en Cataluña como consecuencia de los resultados electorales del 27 de Septiembre de 2015» (Resolución, 1/XI, de 9 de noviembre del 2015), cuyos contenidos son por todos conocidos. También en este punto, los pronunciamientos del Tribunal han sido los que cabía esperar del órgano que tiene principalmente encomendada la defensa de la Constitución e impecablemente coherentes con su doctrina previa:

- El Tribunal, en efecto, como no podía ser de otra forma, ha defendido en primer lugar, lo que con rotunda claridad dice el art. 1.2 de la Carta Fundamental, «que la soberanía nacional reside en el pueblo español, del que emanan los poderes del Estado». Este precepto, que es base de todo nuestro Ordenamiento jurídico, «atribuye — ha dicho el Tribunal en su STC 42/2014 - con carácter exclusivo la titularidad de la soberanía nacional al pueblo español, unidad ideal de imputación del poder constituyente y, como tal, fundamento de la Constitución y del Ordenamiento jurídico y origen de cualquier poder político (SSTC 12/2008, FJ4; 13/2009, FJ 16 y 31/2010, FJ 12). Si en el actual ordenamiento 
constitucional solo el pueblo español es soberano, y lo es de manera exclusiva e indivisible, a ningún otro sujeto u órgano del Estado o a ninguna fracción de ese pueblo puede un poder público atribuirle la cualidad de soberano. Un acto de este poder — sigue el Tribunal— que afirme la condición de «sujeto jurídico « de soberanía como atributo del pueblo de una Comunidad Autónoma no puede dejar de suponer la simultánea negación de la soberanía nacional que, conforme a la Constitución, reside únicamente en el conjunto del pueblo español». «El reconocimiento al pueblo de Cataluña de la cualidad de soberano, no contemplada en nuestra Constitución para las nacionalidades y regiones que integran el Estado, resulta incompatible con el art. $2 \mathrm{CE}$, pues supone conferir al sujeto parcial del que se predica dicha cualidad el poder de quebrar, a su sola voluntad, lo que la Constitución declara como su propio fundamento en el citado precepto constitucional: «la indisoluble unidad de la nación española» (STC 42/2014, FJ 3). Consecuencia de esta firme doctrina han sido, primero, la declaración de inconstitucionalidad y nulidad del principio primero, el titulado «Soberanía» de la primera Declaración impugnada y, segundo, la declaración de inconstitucionalidad y nulidad de la totalidad segunda.

- Estas declaraciones de constitucionalidad y nulidad, sin embargo, no han supuesto la deslegitimación por parte del Tribunal de las aspiraciones de quienes desean un marco distinto del que supone la Constitución del 78. Antes al contrario, el Tribunal ha manifestado, a mi parecer, gran sensibilidad jurídica y política, al ver en el «llamado derecho a decidir» una aspiración política defendible en el marco de la Constitución, y al recordar su doctrina también tradicional, de que «la primacía de la Constitución no debe confundirse con una exigencia de adhesión positiva a la norma fundamental» y de que «el planteamiento de concepciones que pretendan modificar el fundamento mismo del orden constitucional tiene cabida en nuestro ordenamiento, siempre que no se vulneren los principios democráticos, los derechos fundamentales o el resto de los mandatos constitucionales, y el intento de su consecución efectiva se realice en el marco de los procedimientos de reforma de la Constitución, pues el respeto a estos es, siempre y en todo caso inexcusable (STC 103/2008, FJ4)» (STC 42/20014, FJ4). Dicho en otros términos, el Tribunal ha tenido buen cuidado en que sus resoluciones no puedan leerse como instrumentos para sofocar o deslegitimar el debate político en curso, en particular, por decirlo en los términos de nuestra resolución, el derivado «de la voluntad de una parte del Estado de alterar su estatus jurídico», pero ha recordado y exigido el respeto a la Constitución y a la ley a quienes pretenden llevar ese proyecto a cabo. «El debate público, dentro o fuera de las instituciones, sobre tales proyectos 
políticos o sobre cualesquiera otros que propugnaran la reforma constitucional goza, precisamente al amparo de la misma Constitución, de una irrestricta libertad. Por el contrario, la conversión de esos proyectos en normas o en otras determinaciones del poder público no es posible sino mediante el procedimiento de reforma constitucional. Otra cosa supondría liberar al poder público de toda sujeción al Derecho, con daño irreparable para la libertad de los ciudadanos» (STC 259/2015, FJ 7).

\section{ANTE EL HORIZONTE DE UNA REFORMA CONSTITUCIONAL}

Para cerrar este trabajo, quisiera reflexionar brevemente sobre la eventualidad, que cada día parece más hacedera, de una reforma de la Constitución, que sobre todo parece necesaria en el tema que nos ocupa. Yo ya me he pronunciado sobre la necesidad de abordar la reforma ${ }^{8}$ porque creo que reformar la Constitución es la mejor forma de garantizar su perdurabilidad y eficacia y de renovar el consenso social que la legitima.

Pero permítaseme que primero aluda a las pautas procedimentales que, a mi juicio, debieran regir el proceso de reforma, para centrarme luego en arriesgar algunas propuestas sustantivas, relativas aquellos concretos contenidos del Título VIII de la Constitución que, a la luz de mi experiencia como juez constitucional, postularía abordar.

Las primeras debieran resultar ociosas, pero visto lo visto - me refiero a la urgencia y la premura con la que algunos plantean las reformas y la desenvoltura con que se formulan y retiran las propuestas- quizás no lo sean tanto. La reforma de la Constitución debe ser el resultado de un proceso de debate y reflexión sosegado - la reforma del art. 135 de la Constitución no constituye en este sentido ningún ejemplo — y de una amplia negociación política que intente, en la medida de lo posible, repetir los consensos que se alcanzaron en 1978. No existen hoy las premuras que existían en 1978 - tenemos una Constitución que mal que bien cumple adecuadamente la función que le corresponde- y debiéramos intentar evitar los errores en los que entonces se incurrió, señaladamente, por lo que se refiere al tema que nos ocupa, dejar el modelo territorial del Estado permanentemente abierto e inacabado en la definición de sus elementos estructurales y al abur del juego partidario. En este sentido, los tiempos de reforma que requieren los procedimientos establecidos en los artículos 167 y 168 de la Constitución son seguramente una garantía de acierto?.

8 Pérez De Los Cobos, F, «La vigencia de la Constitución», ABC, 6.12.2013.

9 Rubio Llorente, F, «Sobre la posibilidad de reformar la Constitución y la conveniencia de hacerlo», La forma del poder. Estudios sobre la Constitución, Tomo II, CEPC, $3^{\mathrm{a}}$ ed, Madrid 2012 p. 827. 
Creo que, en segundo lugar, la envergadura de la reforma debiera ser limitada y focalizada sobre aquellos aspectos que la precisen y sobre los que sea factible el acuerdo. El «bipolarismo» hispánico no debiera llevarnos de la sacralización de un texto, que como todos, era y es perfectible y mejorable, a su impugnación general, pues son muchos los aspectos — la inmensa mayoría me atrevería a decir- en los que la Constitución ha funcionado y funciona adecuadamente. Por poner sólo un importante ejemplo, por lo que se refiere a la protección de los derechos y libertades de los ciudadanos, España es uno de los países signatarios del Convenio de Roma que menos condenas padece del Tribunal Europeo de Derechos Humanos, circunstancia que como el propio presidente del Tribunal europeo ha destacado se explica por la eficacia de nuestro sistema constitucional de protección de derechos y libertades ${ }^{10}$. Por tanto, reforma de la Constitución sí pero para perfeccionar el texto vigente, enmendándolo solo en aquellos extremos en los que resulte necesario y factible. Como ha sido justamente advertido, a la hora de abordar las reformas legales y, en particular las constitucionales, conviene evitar el pensamiento mágico ${ }^{11}$ porque la capacidad de las normas para conformar y transformar la realidad es siempre limitada. Por tanto, selección y selección rigurosa de las reformas constitucionalmente necesarias, prescindiendo, desde luego, de pretender rango constitucional para aquellas reformas que el legislador puede fácilmente acometer sin necesidad de modificar la Constitución. Por poner de nuevo un ejemplo, la gran mayoría de las reformas tendentes a satisfacer las exigencias de regeneración democrática que la sociedad demanda pueden seguramente acometerse modificando las leyes orgánicas y ordinarias pertinentes sin necesidad de alterar el texto constitucional.

Hay una última reflexión metodológica, si se la quiere denominar así, que no me resisto a formular. La reforma de las instituciones sociales debe llevarse a cabo desde el atento análisis de su funcionamiento, prestando sobre todo atención a los comportamientos humanos que han acompañado su praxis, pues presumiblemente, salvo que se ponga adecuado remedio, tenderán a reproducirse. Rousseau decía que «las buenas instituciones sociales son las que mejor saben desnaturalizar al hombre», sin atreverme a tanto, diría — y creo que la reflexión es particularmente pertinente en el ámbito que nos ocupa- que si queremos evitar reproducir los errores que del análisis de la realidad hemos detectado, conviene modificar aquellas técnicas y prácticas regulatorias que en su implementación han producido resultados indeseados y abundar en la previsión de instrumentos que permitan caminar en sentido contrario. Para ello contamos con el precioso acervo que han sido estos treinta y nueve años de experiencia constitucional —en el que los treinta y siete años de jurisprudencia constitucional constituyen un

10 Spielmann, D, «Discours du Président Dean Spielmann Cour européenne des drois de 1’homme», Seminario en el Tribunal Constitucional, Madrid 22 de Mayo 2015, p. 5.

11 Herrero De MiÑón, M, 1812- 1978, dos constituciones en entredicho, Galaxia Gútember Círculo de Lectores, Madrid 2013, p. 225. 
patrimonio impagable- , cuyo análisis detenido y profundo debiera ser el presupuesto de partida para identificar aquellos aspectos que debieran reformarse y para pergeñar los proyectos de reforma.

Desde esta perspectiva, paso a identificar los extremos que, desde mi punto de vista, podrían centrar la reforma del Título VIII de la Constitución, una reforma que, a mi entender, debiera - y es muy importante tener bien claro lo que se pretende- intentar paliar o minimizar la dimensión conflictual de nuestro modelo de Estado, innecesariamente desmesurada y en la que el Tribunal Constitucional se ha visto comprometido al tener que desempeñar un papel protagonista. Se trataría, por tanto, en primer lugar de reformular aquellas previsiones constitucionales que se han manifestado particularmente problemáticas y, en segundo lugar, de completar la regulación con principios, técnicas e instrumentos que contribuyan a armonizar y pacificar el funcionamiento del sistema. Soy bien consciente de que un modelo de Estado compuesto y complejo como el nuestro es por su propia naturaleza conflictual, pero precisamente por ello conviene dotarlo de los mecanismos que permitan aplacar, canalizar y resolver los conflictos.

Repasando la bibliografía que ya ha abordado la cuestión ${ }^{12}$ detecto un consenso de base, en el que coincido, sobre los aspectos que debieran reformarse, no tanto sobre el modo en el que la reforma deba a hacerse, pero ello resulta incluso positivo para lo que debiera ser un rico y amplio debate tanto técnico como político:

1. El primer aspecto que entiendo debe acometerse es el de reescribir para clarificar en la propia Constitución el sistema de distribución de competencias entre el Estado y las Comunidades Autónomas, de manera que se mejore la eficiencia en el ejercicio de la actividad de los poderes públicos y se reduzca la excesiva conflictividad institucional. No me atrevo a terciar en el debate sobre cual es la técnica más adecuada para conseguir estos propósitos, si el sistema de lista única, propuesto por algún sector de la doctrina constitucionalista, o el de dos y

12 Rubio Llorente, F, «Sobre la posibilidad de reformar la Constitución y la conveniencia de hacerlo", en La forma del poder. Estudios sobre la Constitución, Tomo II, CEPC, $3^{\mathrm{a}}$ ed, Madrid 2012; Herrero De Miñón, M, 1812- 1978, dos constituciones en entredicho, Galaxia Gútember Círculo de Lectores, Madrid 2013; Muñoz Machado, S, Crisis y reconstitución de la estructura terriorial del estado, Ed. Iustel, Madrid 2013; Rubio llorente, F; Navarro, P; Tornos Más, J; Solozabal Echevarría, J.J.; De Carreras Serra, F; CaAmaño Domínguez, F, Una propuesta de federalización, Madrid 2014; García Roca, J, Pautas para una reforma constitucional, Thomson Reuters Aranzadi, 2014; AA.VV., «Sobre la reconstrucción del estado autonómico», en El Cronista del Estado Social y Democrático de Derecho, n 51, 2015; López AGuiLAR, J.F; «Reformar la Constitución, ahora. Antes de que sea ya tarde», en El Cronista del Estado Social y Democrático de Derecho, $\mathrm{n}^{\circ}$ 53-54; BAÑo LEón, J.M (coord.). Memorial para la reforma del Estado. Estudios en Homenaje al profesor Santiago Muñoz Machado, T.II, CEPC, 2016; MuÑOz MACHADO, S, Vieja y nueva Constitución, Crítica, Barcelona 2016; Herrero De Miñón, M, Tres conferencias sobre la reforma constitucional, Tirant Lo Blanch, Valencia 2016. AAVV, «La crisis del Estado de las autonomías», en Teoría y Derecho, nº 19, Junio 2016; GómeZ- Ferrer Morant, R, Deconstrucción del sistema jurídico y reforma de la Constitución, RACMP, Madrid 2016; DE CARRERAS SERra, F, Ensayos sobre el federalismo, RACMP, Madrid 2016. 
hasta tres, que parecen contar con mayor respaldo, pero sí quisiera ofrecer algunos criterios que, a mi entender, debieran informar cualquier intento de reformulación del sistema, a la luz de la experiencia que nos ofrece el modelo vigente. El primero es que la reforma del modelo debiera tener como principal objetivo el de conseguir la mayor eficiencia de los poderes públicos en el desempeño de sus funciones, lo que debiera redundar en favor de los ciudadanos, destinatarios últimos de la actividad política y administrativa. No debiera tratarse, por lo tanto, de dotar, porque sí, de más competencias a las Comunidades Autónomas en detrimento del Estado o a éste en detrimento de aquellas, sino de diseñar un sistema que, teniendo bien presente el objetivo expuesto, determine quién puede desempeñar más adecuadamente las funciones de que se trate y ofrezca al titular de la competencia seguridad jurídica para ejercerla. Al abordar este asunto, hay en el derecho comparado, y este es el segundo criterio que quisiera ofrecer, modelos acreditados de distribución territorial del poder que debieran servir de pauta para acometer esta reforma, obviamente sin perjuicio de las adaptaciones y modulaciones que puedan requerir las singularidades de nuestro sistema. La tercera pauta, en fin, que me permito señalar es la necesidad de limitar y clarificar en el texto constitucional el recurso a la técnica bases/desarrollo que tanta conflictividad ha generado y genera. Al respecto propondría un cuidadoso análisis de aquellas materias en las que este reparto sea necesario, excluyéndolo cuando no lo sea, así como la incorporación al texto constitucional de estas categorías, clarificando en la medida de lo posible su alcance desde las perspectivas formal y material, así como constitucionalizar las técnicas de cooperación y coordinación.

2. El segundo aspecto, también relativo a la distribución e interacción de competencias entre el Estado y las Comunidades Autónomas, sobre el que creo necesario incidir, es la regulación de los diversos principios constitucionales llamados a presidir las relaciones entre el Estado y las Comunidades Autónomas y de éstas entre sí: el principio de lealtad constitucional, el principio de solidaridad, el de igualdad de todos los españoles en las diversas partes del territorio, y los principios de prevalencia y subsidiariedad. Creo que el potencial interpretativo de estos principios es muy grande y que quizás por la imprevisión expresa de algunos y por la defectuosa formulación de otros en el texto constitucional, el Tribunal Constitucional no ha sabido extraer de los mismos todas sus virtualidades, que pueden ser muchas. Estoy persuadido de que una correcta formulación de los mismos que los ponga en valor y garantice su eficacia puede contribuir significativamente a la integración y articulación del conjunto del sistema autonómico ${ }^{13}$.

13 En el mismo sentido, Rubio Llorente, F, «Sobre la posibilidad de reformar la Constitución y la conveniencia de hacerlo», La forma del poder. Estudios sobre la Constitución, Tomo II, CEPC, $3^{\mathrm{a}}$ ed, Madrid, 2012 p. 833 . 
3. El tercer ámbito de reforma sobre el que creo necesario incidir, y que creo podría dar una nueva impronta al modelo es el de la institucionalización en la Constitución de los instrumentos políticos que pueden servir — que están sirviendo ya- a la prevención, negociación y composición de los conflictos competenciales, dándoles el protagonismo y la entidad que merecen, de suerte que el recurso al Tribunal Constitucional se configure como lo que debiera ser, como una «ultima ratio». Si se repara bien, el extraordinario protagonismo que en la resolución de los conflictos territoriales ha correspondido al Tribunal Constitucional es, en buena medida, consecuencia de la práctica total ausencia de otros instrumentos y mecanismos practicables para evitarlo y solventarlo. Pues bien, institucionalizar en la propia Constitución estos instrumentos políticos que puedan prevenir, minimizar y, en su caso, solventar los conflictos puede ser un expediente eficaz para apaciguar el sistema. Creo que la experiencia acredita $-\mathrm{y}$ ahí está el caso de las Comisiones Bilaterales del art. 33.2 LOTC de ejemplo- que también el órgano hace a la función y que si se habilitan instrumentos para la composición del conflicto estos se utilizan y la conflictividad merma.

Dejando a un lado la cuestión de la reforma del Senado, sobre la que no tengo criterio formado y que desborda con mucho las pretensiones de mi reflexión, concretaría mi propuesta en la regulación constitucional de dos instrumentos ya existentes, las conferencias de Presidentes y las conferencias sectoriales, formalizando su composición, el amplio catálogo de funciones a desempeñar — entre las que debe contemplarse expresamente la elaboración de aquellos proyectos normativos que incidan sobre las competencias autonómicas y la cooperación y coordinación en el desarrollo de las competencias compartidas-, la periodicidad de sus convocatorias y el contenido y eficacia de sus acuerdos ${ }^{14}$.

4. Un último aspecto, en fin, que creo conveniente que la reforma constitucional aborde es el de la repercusión de nuestra pertenencia a la Unión Europea sobre el sistema constitucional de competencias. Ya hemos visto que, conforme a nuestra doctrina —que quizás fuera conveniente incorporar al texto constitucional- el Derecho comunitario no puede servir de título para alterar el orden constitucional y estatutario de competencias, que se mantiene incólume. Esta previsión, sin embargo, coexiste con la plena responsabilidad del Estado en cuanto que garante último, del cumplimiento del Derecho comunitario (art. 93 in fine CE), también cuando el incumplimiento se produce por parte de las Comunidades Autónomas encargadas de aplicarlo o trasponerlo. Pues bien, nuestro ordenamiento que ya ha previsto mecanismos de repercusión de responsabilidad para el caso del incumplimiento

14 La Ley 40/2015, de 1 de Octubre, de Régimen Jurídico del Sector Público ha dado importantes pasos en esta institucionalización que postulamos, pero el Consejo de Estado ha expresado serios y fundados reparos a que en una Ley relativa a la organización y funcionamiento de la Administración General del Estado entre a regular cuestiones que atañen a la distribución constitucional de competencias y debieran merecer texto legal distinto y dictarse al amparo del 149.1.18 CE (Dictamen $n^{\circ}$ 274/2015).as itucional de competencias y atañen a la distribucitribucia que en una Ley relativa a la organizaciio, que tambida a evitar el 
autonómico del Derecho de la Unión, no ha hecho lo que juzgo sería más necesario: dotarse de mecanismos preventivos que permitan evitarlo. A mi juicio, en este ámbito habría que dotar al Estado, en cuanto que responsable último del incumplimiento del Derecho de la Unión, de instrumentos de coordinación «ex ante» que permitieran garantizar la adecuada ejecución y transposición del mismo cuando en ellas se vean involucradas las Comunidades Autónomas y prever para los supuestos en los que se persevere en el incumplimiento, el juego del principio de supletoriedad del derecho estatal, pues hoy como ha dicho el Tribunal de Justicia de la Unión Europea en su STJUE de 24 de Octubre del 2013, (Comisión c. Reino de España. As. C-151/12) este mecanismo no cumple las exigencias mínimas de especificidad, precisión, claridad y seguridad jurídica para considerar cumplida la obligación de transposición.

$$
* * *
$$

TITLE: The role of the Constitutional Court in the Autonomy State

ABSTRACT: The present essay aims to be a thought about the important role played by the Constitutional Court in the build-up of the Autonomy State. Its origins could be found, as far as it is known, in the not plenty definition of the territorial model in the Spanish Constitution, pushing the Court to play a role maybe a little bit to excessive. In the text we show some examples of that building, with the remarkable point of a coherent reasoning. At the end we set a bunch of proposals of constitutional reforms, trying to set some tools to prevent and solve the inevitable conflicts that take place.

RESUMEN: El presente ensayo quiere ser una reflexión sobre el importantísimo papel que al Tribunal Constitucional ha correspondido en la construcción del Estado autonómico. El origen de este papel se encuentra, como es sabido, en la indefinición del modelo territorial del Estado de la Constitución del 78, que ha obligado al Tribunal a una labor de construcción jurídica de primer orden y a desempeñar un protagonismo probablemente excesivo. En el texto se ofrecen algunos ejemplos de esa labor de construcción jurisprudencial y se señalan las limitaciones inevitables de este «modus operandi». Reflexionando sobre la labor de defensa del modelo autonómico realizada por el Tribunal, se destaca la notable coherencia doctrinal con la que ha sabido hacer frente a los distintos desafíos que se han sucedido, poniendo coto tanto a los intentos de minimización como de desbordamiento del modelo. El ensayo se concluye con algunas propuestas para debate sobre la reforma constitucional, inspiradas por el propósito de apaciguar el modelo territorial y dotarlo de instrumentos capaces de prevenir, minimizar y/o resolver los inevitables conflictos.

KEY WORDS: Constitutional Court, Territorial Model, Constitutional Reform.

Palabras Clave: Tribunal Constitucional, Modelo Territorial, Reforma Constitucional.

FECHA DE RECEPCIÓN: 18.06.2017

FECHA DE ACEPTACIÓN: 26.07.2017 